\title{
MEASLES CONTROL CAMPAIGN
}

\section{PUBLIC HEALTH EDITORIAL STAFF}

The NSW Public Health Bulletin is a publication of the NSW Department of Health. The editor is Dr Lynne Madden, Manager, Public Health Training and Development, NSW Health Department. Rhana Pike is production manager.

The Bulletin aims to provide its readers with population health data and information to motivate effective public health action.

\section{Submission of articles}

Articles, news and comments should be 1000 words or less in length and include a summary of the key points to be made in the first paragraph. References should be set out in the Vancouver style, described in the New England Journal of Medicine, 1997; 336: 309-315. Send submitted articles on paper and in electronic form, either on disc (Wordperfect or Word for Windows are preferred), or by email. The article must be accompanied by a letter signed by all authors. Full instructions for authors are available on request from the editor.

\section{Editorial correspondence}

Please address all correspondence and potential contributions to The Editor, NSW Public Health Bulletin, Locked Mail Bag 961, North Sydney NSW 2059 or to Lmadd@doh.health.nsw. gov.au. Tel (02) 9391 9956, Fax (02) 93919232.

\section{Distribution}

Please contact your local Public Health Unit or telephone (02) 93919942 to obtain copies of the NSW Public Health Bulletin or to notify us of a change of address. The Bulletin can be accessed via the Internet from http:// www.health.nsw.gov.au/public-health/phb/phb.html, the Department's Web site.

Back issues can be obtained from the Better Health Centre, Locked Mail Bag 961, North Sydney NSW 2059. Tel (02) 9954 1193, Fax (02) 99555196.
Recently the Federal Minister for Health, Dr Michael Wooldridge, announced funding for the National Enhanced Measles Control Program, which will be conducted from August to November 1998. The NSW Minister for Health, Dr Andrew Refshauge, has endorsed and pledged his support for this campaign.

The Measles Control Campaign will aim to:

- Ensure that all primary school children are provided with a second dose of the measles (measles-mumpsrubella (MMR)) vaccine, through a school-based delivery program. The NSW Health Department will be targeting 2100 primary schools during this campaign.

- Follow up all two- to five-year-olds, in cooperation with general practitioners and other immunisation providers, to ensure that they have received their first dose of MMR vaccine.

- Ensure that all secondary students are advised to make sure that they have received their MMR booster (second) dose.

The Commonwealth Government will provide $\$ 30$ million nationally to fund this important campaign, from which NSW will receive \$2 130680 . This will cover the purchase of vaccines, the employment of a state measles coordinator, nursing and clerical assistance and a multilayered integrated communication campaign. The aim is to achieve the National Health and Medical Research Council objective of 95 per cent coverage of school-age children for measles.

The NSW Health Department has employed Ms Jan Broome as the State Measles Immunisation Coordinator to facilitate the Enhanced Measles Control Program. Ms Broome will coordinate the implementation of the campaign in metropolitan Areas. Teams of nurses will be employed to vaccinate primary school children in these Areas. Rural immunisation coordinators will be responsible for implementation of the campaign in the respective rural Areas.

The Commonwealth is planning an extensive education campaign aimed at parents of primary school-aged children, parents of preschool-aged children, parents of high school children, general practitioners and teachers. The public education campaign commenced on 12 July 1998. 